Methods The local high school was approached in January 2018 with the idea of establishing a 'twinning programme' where six students would visit the hospice and engage in four follow-up workshops to develop a presentation on their impressions. Students also completed a short pre- and postvisit questionnaire to elicit their beliefs about hospices and subsequent learning.

Results The initial questionnaire indicated limited awareness of hospice care and the associated business functions but immediate verbal feedback after the first visit saw a greater appreciation of the range of healthcare professionals employed, the services offered and the 'feeling' of being in the hospice building. The students created a poster and short video with the theme of 'It's not just...' to summarise the stereotypical views of hospices and counter these with their experiences and interviews with hospice staff. In addition, the school has held a fundraising event and three students have organised work experience placements.

Conclusion The project work is to be displayed publicly at the school and hospice. The acknowledged benefits so far include students' development of core skills in observation, communication, reflection and teamwork while hospice staff have gained valuable experience in interdisciplinary co-design and opening the hospice to a younger audience. It is hoped that further school twinning projects will be established and stimulate more students to consider the hospice as a work experience provider.

\section{P-31 THE ART OF STIMULATING CONVERSATION}

Denise Williams, Rachel Shovelton. East Lancashire Hospice, Blackburn, UK

\subsection{6/bmispcare-2018-hospiceabs.56}

Rationale In our society people are fearful of illness, death and bereavement and find it difficult to talk about these issues. Research indicates that having positive and honest conversations about these topics improves people's experience of these events when they occur in their life.

Aim To stimulate people in our community to have open, positive conversations about illness, death and bereavement

Method Successful bid for a project manager to run a pilot in 2017. Research into how to encourage conversations about difficult topics. Invited participation from; community groups, schools, colleges, universities, care homes, and youth groups. Held a workshop explaining the aim of the project. Provided art materials donated free of charge by a local supplier. Provided interim support visit. Held exhibitions of work produced in the community and at the hospice during Dying Matters Week. Evaluation of impact. Reach and impact of the project expanded to care homes, universities and high schools in 2018. Investment one day a week for one member of staff.

Results

- Workshops provided to 187 participants

- 944 people attended the exhibitions

- Significant increase in the percentage of people thinking about and having conversations about illness, death and bereavement

- Partnership working with local community increasing awareness of the hospice and services
- Production of amazing art and performance that has demonstrated impact

- Income generation through donations at exhibitions

- Access to free art materials for project and hospice services

- Donation of art work for the hospice environment

- DVD of performances to inform education

- Representatives accessing bereavement education provided by the hospice.

Conclusion The Arts provide a valuable opportunity to work with communities to stimulate conversations about illness, death and bereavement and establish mutually beneficial links between the hospice and our community. This project is fun, rewarding and easily replicated in other communities.

\section{P-32 MATERIAL LEGACIES, IN THE LANDSCAPE OF THE LOST, 2017}

Annalie Ashwell. The Hospice of St Francis, Berkhamsted, UK

10.1136/bmispcare-2018-hospiceabs.57

An exhibition to engage the local community and enable conversations about death and dying.

Background The exhibition was the final re-staging of the artworks generated during a collaborative five-year $\mathrm{PhD}$ research project between the hospice, three bereaved stakeholders and designer, Dr. Stacey Pitsillides. The exhibition ran for two weeks in a local arts venue and provided research collaborators with the opportunity to become local ambassadors. Throughout the exhibition the hospice ran events including an outpatient centre 'taster day', a creative therapies education day and a life drawing class.

Aims To utilise the exhibition of artworks created by three bereaved women as a means of engaging the local community in discussions around death, dying and bereavement, and to raise awareness and visibility of hospice services.

Methods To install the exhibition in an easy-to-reach and accessible venue located on the high street of the local hospice town. To deliver events to engage the community and increase understanding of hospice services.

Results Results gathered from 21 visitor feedback forms:

- 19 people said that after visiting the exhibition they would feel more inclined to access hospice support services

- On a scale of 1-10 (1 being not at all - 10 being very well), 17 people scored $8+$ in how important it is to talk about death and dying in the local community

- Words captured describing the exhibition: 'inspiring, amazing, interesting, enlightening, necessary, thought provoking, clever, innovative, refreshing, insightful, challenging, sincere'

In addition 40 people attended the 'taster day' and 13 allied health professionals attended the creative therapies education day.

Conclusion The arts are a powerful vehicle to engage communities in difficult and challenging conversations about death and dying and taking services off-site can help to raise awareness and increase understanding of hospice services. 